\title{
Aspectos Críticos na Aprendizagem pela Ação: Resultados da Integração entre Universidade e Startups Catarinenses
}

\author{
Critical Aspects of Action Learning: Results of \\ Integration Between University and Brazilian Startups
}

\author{
Rogério Tadeu de Oliveira Lacerda \\ Mayara Lucia Bernardes \\ Bianca dos Santos Simon
}

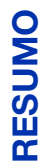

\begin{abstract}
Este artigo visa evidenciar os fatores críticos na aplicação de um método de aprendizagem pela ação em um projeto de extensão na Universidade Federal de Santa Catarina. Os procedimentos práticos propostos pelo projeto são baseados na abordagem construtivista de aprendizagem. Utilizou-se a abordagem qualitativa para coleta de dados, sendo o método aplicado de estudo de caso. Como resultados, foi possível observar alguns fenômenos quanto ao comportamento dos alunos, a busca de uma solução ótima e genérica de problemas a partir da literatura científica ou de exemplos semelhantes. Outro aspecto observado foi o entendimento, por parte dos alunos que a organização interna e o gerenciamento de aprendizado são mais importantes do que a solução técnica em si. A singularidade do problema de startup, aliada à limitação de fatos e dados, levou o grupo a decidir mais sobre estudos in loco na startup do que em pesquisas bibliográficas genéricas sobre o problema. Como implicações práticas desta pesquisa destaca-se a contribuição para educadores e facilitadores que lidam com problemas de natureza incerta e dinâmica.
\end{abstract}

Palavras-chave: Aprendizagem pela ação. Construtivismo. Avaliação de desempenho. EBTs. Incerteza.

This article aims to highlight the critical factors in the application of an action learning method in an extension project at the Federal University of Santa Catarina. The practical procedures proposed by the project are based on the constructivist approach to learning. A qualitative approach was used for data collection, and the applied method of case study. As a result, it was possible to observe some student behavioral events, the search for an optimal and generic problem solution from the scientific literature or similar examples. Another aspect observed was students' understanding that internal organization
Recebido em: 10/12/2019 Aprovado em: 25/04/2020

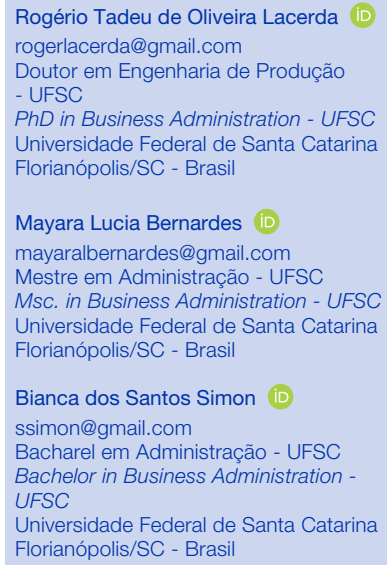


and learning management are more important than the technical solution itself. The uniqueness of the startup problem, coupled with limited facts and data, led the group to decide more about studies at an on-site startup than generic bibliographic research on the problem. Practical implications of this research include the contribution to educators and facilitators dealing with problems of uncertain and dynamic nature.

Keywords: Action learning. Constructivism. Performance evaluation. EBTs. Uncertainty.

\section{Introdução}

Atualmente, cada vez mais exige-se competências diferenciadas das empresas para que estas se sobressaiam diante do cenário competitivo atual (TEECE, 2012). Esta nova demanda por diferenciais se intensificam em ambiente dinâmicos, principalmente para empresas que possuem a tecnologia o seu core business, aqui denominadas como Empresas de Base Tecnológica - EBTs (LACERDA et. al., 2017; ZOTT; AMIT, 2017).

Contudo, mesmo a partir destas novas demandas, as EBTs apresentam desafios no que tange a gestão, e principalmente empresas menores, enfrentam dificuldades para o crescimento (HUDSON; SMART; BOURNE, 2001). Deste modo, cada vez mais estas empresas buscam nas universidades, profissionais preparados para assumirem cargos gerenciais. E, diante desta nova necessidade, é demandada das instituições de ensino a formação de profissionais preparados à nova realidade (BENI et al., 2017).

Nesse contexto desafiador, emerge a importância da reflexão sobre os métodos de ensino e aprendizagem aplicados nas instituições de ensino. Com isso, a medida que o ensino em administração evolui, a utilização de novos recursos, como forma de facilitação da aprendizagem, assim como representações da experiência a ser vivida constitui um campo didático promissor ( CANOPF et al., 2018).

Deste modo, um dos métodos de ensino que vêm ganhando espaço dentro do ensino de administração é a aprendizagem pela ação. O aprendizado pela ação sugere que os alunos façam atividades de aprendizado significativas e pensem sobre o que estão fazendo (PRINCE, 2004) e assim, contribui para o desenvolvimento de competência através do contato direto com problemas reais, incentiva a reflexão 
sobre a relação da ação e suas consequências, compartilhamento de experiências e trabalho em equipe (MARQUARDT, 2005).

Dessa forma, a partir do contexto em que estas EBTs estão inseridas, surge a necessidade de projetos de pesquisa e extensão que auxiliem na formação de alunos com o objetivo de auxiliar estas empresas a utilizarem novos conceitos, tendências e ferramentas para seu sucesso empresarial, no contexto de um programa universitário que se centra em uma abordagem de aprendizagem ativa (CALVETTI; LACERDA; BERNARDES, 2019).

Diante do exposto, esta pesquisa tem por objetivo evidenciar os fatores críticos na aplicação de um método de aprendizagem pela ação em um projeto de extensão na Universidade Federal de Santa Catarina, tendo os seguintes objetivos específicos: i) propor um método de aprendizagem ativa para aperfeiçoar competências em alunos de graduação; ii) explanar os resultados da execução de um projeto de extensão se valendo do método de aprendizagem pela ação; iii) triangular evidências para propor aspectos críticos do método de uma forma indutiva.

\section{Fundamentação Teórica}

\section{APRENDIZAGEM PELA AÇÃO}

Cada vez mais, para transformar estudantes em profissionais preparados, os cursos de graduação, além das competências técnicas das suas áreas de conhecimento, precisam preparar para o mercado de trabalho profissionais para o uso intenso da criatividade, comunicação, trabalho em equipe e estruturação de problemas complexos, incertos e conflituosos.

Diante desta necessidade de perfil profissional derivado de um mercado competitivo baseado em inovação, a mudança nos métodos de ensino se torna essencial, uma vez que os métodos tradicionais de ensino não contribuem para o desenvolvimento destas competências requeridas (PERRITON; REYNOLDS, 2018). As abordagens passivas de aprendizado, fundamentados principalmente na verbalização de conteúdo tem se revelado uma estratégia de ensino pouco eficiente (MARQUARDT, 2005; LEONARD, 2015). 
Neste sentido, Leonard e Lang (2010) argumentam que a revitalização do processo de ensino-aprendizagem possibilita que aluno seja o principal agente da construção de seu conhecimento e não apenas um receptor de dados e informações. Diante disso, é necessário que os alunos desenvolvam sua capacidade crítica, de conceituação e de autonomia realizando tarefas mentais de alto nível, como análise, síntese e avaliação (BARON, 2016). Com isso, a partir das reflexões apresentadas acima, emerge o primeiro constructo teórico desta pesquisa:

Constructo 01: Como forma de uma aprendizagem efetiva, é preciso que os alunos desenvolvam sua capacidade crítica, de síntese, de conceituação e de autonomia realizando tarefas mentais de alto nível, como análise, síntese e avaliação.

Deste modo, um dos métodos de ensino que vêm ganhando espaço dentro do ensino de administração é a aprendizagem pela ação (BENI et al., 2017; PERRITON; REYNOLDS, 2018). Em suma, aprendizado pela ação - APA estabelece que os alunos façam atividades de aprendizado significativas e reflitam sobre o que e como estão executando. Ou seja, o aprendizado pela ação contribui para o desenvolvimento de competências por meio do contato direto com o objeto de estudo, reflexão sobre a relação da ação e suas consequências, compartilhamento de experiências e trabalho em equipe (KRAKAUER; DOS SANTOS; DE ALMEIDA, 2017).

E, neste sentido, a APA tem como premissas e princípios: (i) estabelecer uma relação entre ação e aprendizagem; (ii) sustenta que o aprendizado é mais efetivo quando é um processo ativo e não passivo; (iii) estabelece uma relação efetiva entre pratica e teoria; (iv) enfatiza a natureza experimental da aprendizagem e resolução de problemas, vê mudança como um processo iterativo (LEONARD, 2015). Especificamente, Edmonstone (2015) elenca os benefícios da aprendizagem pela ação no nível individual:

- Maior amplitude de compreensão, como base na construção de relacionamentos;

- Melhor capacidade de dar sentido a dados e situações ambíguas e resolução de problemas complexos;

- Capacidade de entender e iniciar mudanças organizacionais; 
- Um enfoque aprimorado no que faz a diferença em uma determinada situação;

- Indivíduos mais focados em ação e proativos na entrega resultados;

- Uma maior autoconsciência do impacto pessoal nos outros, contribuindo para uma capacidade aprimorada de trabalhar em equipes.

Sendo assim, as estratégias que promovem aprendizagem pela ação podem ser definidas como sendo atividades que ocupam o aluno em fazer algo, e ao mesmo tempo, o leva a pensar sobre o que está fazendo. $\mathrm{E}$, neste ponto, existem dois aspectos fundamentais da abordagem de aprendizagem pela ação: (i) o controle do aluno sobre sua própria aprendizagem; e (ii) o aprendizado indutivo (BELL; KOZLOWSKI, 2008).

O primeiro aspecto diz respeito ao controle que o próprio aluno exerce sobre sua aprendizagem, ou seja, o aluno assume a responsabilidade primária por importantes decisões que influenciarão seu aprendizado, como por exemplo, escolhendo atividades de aprendizagem que quer desempenhar, monitorando e avaliando o seu próprio progresso (DE LIMA et. al., 2012; URIAS; AZEREDO, 2017). Em contraponto, as abordagens passivas de aprendizado têm foco na limitação e controle dos alunos, onde o principal agente controlador deve ser o professor, e este assumem a responsabilidade primária pelas decisões de aprendizagem (BELL; KOZLOWSKI, 2008). Deste modo, pode-se destacar como segundo constructo teórico desta pesquisa:

Constructo 02: O aluno deve assumir a responsabilidade sobre decisões que influenciam seu aprendizado, deste modo, deve ter escolha sobre as atividades de aprendizagem que quer desempenhar, monitorando e avaliando o seu próprio progresso.

Em relação ao segundo aspecto da aprendizagem pela ação, destaca-se que promove um processo de aprendizagem indutiva para os alunos (PATON; CHIA; BURT, 2014). Ou seja, os estudantes exploram e experimentam uma tarefa a fim de inferir as regras, princípios e estratégias para um desempenho efetivo. Em contraste, as abordagens passivas para o aprendizado assumem que as pessoas adquirem conhecimento ao ter transmitido a eles por alguma fonte externa. 
No que tange o processo de aprendizagem pela ação, Leonard (2015) apresenta sete fases em que esta se decompõe. Cada fase possui um objetivo especifico que deve ser cumprido no processo de solução do problema e os obstáculos típicos que devem ser superados pela equipe e devem ser considerados aspectos críticos para a aprendizagem dos alunos.

Quadro 1 Estágios, objetivos e obstáculos do processo de aprendizagem pela ação.

\begin{tabular}{|c|c|c|}
\hline Estágio & Objetivo & Obstáculos típicos \\
\hline $\begin{array}{l}\text { Identificação } \\
\text { de problemas }\end{array}$ & $\begin{array}{l}\text { Identificar problemas críti- } \\
\text { cos e urgentes com neces- } \\
\text { sidade de solução }\end{array}$ & $\begin{array}{l}\text { Problemas inapropriados identi- } \\
\text { ficados }\end{array}$ \\
\hline $\begin{array}{l}\text { Seleção de um } \\
\text { problema }\end{array}$ & $\begin{array}{l}\text { Selecionar um dos proble- } \\
\text { mas identificados }\end{array}$ & $\begin{array}{l}\text { Apatia, resistência a retirada de } \\
\text { um problema }\end{array}$ \\
\hline $\begin{array}{c}\text { Analise e } \\
\text { definição do } \\
\text { problema } \\
\text { (causas e en- } \\
\text { quadramento) }\end{array}$ & $\begin{array}{l}\text { Entendimento das princi- } \\
\text { pais causas do problema } \\
\text { selecionado e formulação } \\
\text { do rotulo do problema a ser } \\
\text { resolvido }\end{array}$ & $\begin{array}{l}\text { Análise prematura e incompleta } \\
\text { do problema } \\
\text { Firmar o problema como um } \\
\text { objetivo sem identificar ou com- } \\
\text { preender as causas }\end{array}$ \\
\hline $\begin{array}{l}\text { Geração de } \\
\text { ideias }\end{array}$ & $\begin{array}{l}\text { Identificação de maneiras } \\
\text { de conduzir o problema da } \\
\text { situação atual para o esta- } \\
\text { do futuro delimitado }\end{array}$ & $\begin{array}{l}\text { Julgamento excessivo } \\
\text { Fechamento prematuro do pro- } \\
\text { cesso de geração de ideias } \\
\text { Participação desigual da equipe }\end{array}$ \\
\hline $\begin{array}{l}\text { Avaliação das } \\
\text { ideias }\end{array}$ & $\begin{array}{l}\text { Avaliação dos prós e con- } \\
\text { tras das ideias geradas } \\
\text { Decisão de quais ideias } \\
\text { podem ser implementadas }\end{array}$ & $\begin{array}{l}\text { Falta de um processo efetivo } \\
\text { para consolidar, organizar e ava- } \\
\text { liar as ideias } \\
\text { Influencia desigual dos membros } \\
\text { da equipe } \\
\text { Falha em especificar critérios } \\
\text { para inclusão ou exclusão de } \\
\text { ideias }\end{array}$ \\
\hline
\end{tabular}




\begin{tabular}{|cll|}
$\begin{array}{c}\text { Implementa- } \\
\text { ção das me- } \\
\text { Ihores ideias }\end{array}$ & $\begin{array}{l}\text { Desenvolver um plano de } \\
\text { implementação }\end{array}$ & $\begin{array}{l}\text { Planejamento vago, sem defini- } \\
\text { ção de critérios para acompa- } \\
\text { nhamento de ações, responsa- } \\
\text { bilidades, critérios de sucesso e } \\
\text { cronograma }\end{array}$ \\
$\begin{array}{lll}\text { Avaliação dos } \\
\text { resultados }\end{array}$ & $\begin{array}{l}\text { Desenvolver um plano para } \\
\text { avaliar os resultados }\end{array}$ & $\begin{array}{l}\text { Falta de um plano de avaliação } \\
\text { dos resultados gerados pela } \\
\text { equipe } \\
\end{array}$ \\
& & $\begin{array}{l}\text { Falta de uma análise abrangente } \\
\text { de todo o processo }\end{array}$ \\
\hline
\end{tabular}

Fonte: Adaptado de Leonard (2015)

Ainda neste sentido, o autor ressalta que ao identificar que os alunos de depararam com um obstáculo durante o processo de aprendizagem, o facilitador pode criar perguntas que incentivem a equipe a refletir sobre esse obstáculo, avalie qual é o impacto do desafio e estimule os alunos a decidirem o que precisa ser feito para atingir o objetivo.

Por fim, ressalta-se que os avanços tecnológicos auxiliam, nos dias atuais, as atividades fora e dentro da aula sejam muito mais fáceis e amigáveis aos estudantes, propiciando assim, outra ferramenta de incentivo a aprendizagem ativa (BARBOSA; DE MOURA, 2013; BENI et al., 2017). Atualmente, alunos podem compartilhar arquivos e criar canais de discussão de conteúdo, e assim é possível estabelecer, juntamente com os professores, comunidades virtuais voltadas à aprendizagem (BENI et al., 2017). Diante do exposto, o terceiro constructo teórico apresenta que:

Constructo 03: A partir dos avanços tecnológicos, pode-se propiciar aos alunos ferramentas para a execução de atividades como técnica de incentivo a aprendizagem, como por exemplo, canais de discussão, fóruns de conteúdos e compartilhamentos de arquivos.

\section{GESTÃO DE EMPRESAS DE BASE TECNOLÓGICA - EBTS}

Atualmente, a competição empresarial é influenciada por alguns fatores tais como, a capacidade de inovação, a flexibilidade organizacional e a capacidade de 
mudança (TEECE, 2012). Estes fatores se intensificam em ambientes dinâmicos e incertos, principalmente para empresas que possuem a tecnologia o seu core business, aqui denominadas como Empresas de Base Tecnológica - EBTs (LACERDA et al., 2017; ZOTT; AMIT, 2017).

Neste contexto, a incerteza é uma característica inerente ao processo de tomada de decisão e refere-se a situações em que o tomador de decisão desconhece todas as opções possíveis e suas consequências (ARTINGER et.al., 2015; PICH; LOCH; MEYER, 2002). À medida que a complexidade da decisão aumenta, as soluções se tornam cada vez mais propensas a erros, os meios se tornam mais importantes do que os fins e a racionalização substitui a racionalidade, diferenciando-se assim das situações de 'risco', onde as probabilidades de resultados são conhecidas e a opção ideal pode ser calculada (O'CONNOR; RICE, 2013).

Neste sentido, O‘Connor e Rice (2013) propuseram a diferenciação de quatro tipos de incerteza, a mercadológica, tecnológica, organizacional e de recursos. As incertezas do mercado referem-se a aspectos mercadológicos tais como as necessidades dos clientes, o tamanho do mercado a ser atendido, suas especificidades, entre outros.

Já as incertezas técnicas se referem ao grau em que o conhecimento científico subjacente a empresa é compreendido e pode ser convertido em uma plataforma tecnológica confiável, econômica e fabricável, ou seja, incertezas inerentes a características de produto e desempenho. Seguindo, a incerteza organizacional envolve o risco inerente ao avanço de novas tecnologias ou à criação de novos espaços de mercado e a estrutura organizacional. E, por fim, a incerteza de recursos se refere a atração dos recursos necessários (tanto financeiros quanto baseados em competências) para o desenvolvimento e comercialização do produto (O'CONNOR; RICE, 2013).

Além dessa categorização das incertezas, outra contribuição dessa abordagem é considerar o planejamento inicial de uma nova empresa como uma fase de redução de incertezas por meio de experimentos, na qual o valor é criado quando os empreendedores convertem as suposições em aprendizado (GOMES et. al., 2018). Um empreendedor pode ser capaz de instituir um novo modelo, mas não ser capaz de racionaliza-lo e articulá-lo completamente, dessa forma, a experimentação e a aprendizagem são necessárias (TEECE, 2010). 
Neste ponto, é importante destacar que práticas de gestão para EBTs somente podem ser recomendadas a partir da consideração de suas especificidades, ou seja, de suas características singulares (CHANDLER; BROBERG; ALLISON, 2014; LACERDA et. al., 2017; TEECE, 2010). Neste sentido, pode-se destacar como quarto constructo teórico desta pesquisa:

Constructo 04: As práticas de gestão propostas para EBTs devem ser recomendadas a partir da consideração das especificidades de seu contexto.

\section{ABORDAGEM CONSTRUTIVISTA DE APOIO À DECISÃO}

O presente trabalho baseia-se nas convicções e problemáticas da abordagem construtivista de apoio à decisão. Trabalhando sob a convicção construtivista, os métodos de trabalho permitem levar em conta os aspectos subjetivos de um grupo de decisores, frequentemente permeado com conflitos de interesse provindos de pontos de vistas distintos sobre um mesmo problema (LACERDA et.al., 2016).

Ressalta-se que, as abordagens de decisão apresentam premissas e caminhos, de acordo com o tipo de problema a ser resolvido e da visão epistemológica adotada. Nesta visão, Roy (1993) apresenta quatro abordagens de decisão: normativista, descritivista, prescritivista e construtivista.

A abordagem normativista, permite definir e analisar problemas com base em critérios estabelecidos (ROY, 1993). Dias e Tsoukiàs (2003) argumentam que, este resulta de um modelo racional, onde é possível gerar, ponderar, selecionar alternativas, implementar e avaliar a decisão. Esta abordagem encarrega o decisor a função de selecionar qual o modelo teórico a ser utilizado no processo e para o modelo escolhido coletar os dados do contexto e determinar a solução ótima para o problema (ENSSLIN et.al., 2010; ROY, 1993)

Assim como a abordagem normativista, o descritivismo também é considerado um modelo racional. As duas abordagens utilizam de conhecimentos já existentes, com pouca intervenção do decisor e são aplicadas a situações universais (ENSSLIN et al., 2010; ROY, 1993). Segundo Dias e Tsoukiàs (2003), descritivismo parte da observação de como os decisores tomam suas decisões e vincula a maneira como as decisões são tomadas com a qualidade do resultado obtido. 
Em contraste, as abordagens prescritivista e construtivista se propõem a gerar conhecimentos a partir do decisor e são aplicadas a situações singulares (DIAS; TSOUKIÀS, 2003; ROY, 1993). No prescritivismo, Dias e Tsoukiàs (2003), apresentam que a abordagem busca identificar questões e fornecer uma descrição completa do problema buscando auxiliar na busca de informações para a tomada de decisão.

A abordagem construtivista busca construir modelos específicos ao contexto do tomador de decisão (LACERDA et. al., 2018). Abordagem serve para construir conhecimento no decisor, uma vez que o modelo é construído sobre contexto específico e permite visualizar o impacto das ações, respostas conflitantes são oportunidades de aprendizado, expandindo o conhecimento durante todo o processo (LANDRY, 1995; MARAFON et. al., 2015; ROY, 1993).

Ao escolher a abordagem construtivista como visão de mundo a ser seguida, significa afirmar que o decisor possui papel fundamental, pois ele é a pessoa que tem a responsabilidade e a autoridade necessárias para a tomada de decisão na organização (ROY, 1993; MARAFON et al., 2015; LACERDA et al., 2017).

Constructo 05: O decisor possui papel fundamental, pois ele é a pessoa que exerce responsabilidade e a autoridade necessárias para a tomada de decisão na organização.

Neste contexto, o facilitador do tem a função de construir conhecimento no decisor e pode fazer uso das ferramentas que julgar mais convenientes para que o decisor compreenda os impactos da situação vigente em seu próprio sistema de valores, bem como a evolução causada por suas decisões nos objetivos da organização (ROY, 1993).

Uma vez que o facilitador criou as condições para o decisor expandir seu entendimento sobre seus valores e preferências, então ele vai trabalhar em disponibilizar este conhecimento de forma que o decisor consiga visualizar os efeitos de suas decisões dentro do contexto em questão (ROY, 1993; MARAFON et al., 2015; LACERDA et al., 2017).

Assim, o conhecimento construído apoiará o decisor na identificação das consequências da situação atual e sua evolução, segundo suas decisões emba- 
sadas em seus objetivos estratégicos, gerando assim um processo recursivo de aprendizagem (CALVETTI; LACERDA; BERNARDES, 2019).

\section{INTEGRAÇÃO UNIVERSIDADE-EMPRESA}

As universidades podem estabelecer ligações com a estrutura produtiva que permitam a aceleração da transferência de conhecimento e de tecnologia (MOWERY, 2005). Dessa forma, a presença de uma universidade empreendedora, cujos professores e alunos buscam ativamente os resultados úteis de suas pesquisas é um fator-chave da inovação (ETZKOWITZ; ZHOU, 2017).

A universidade empreendedora é um catalisador em uma economia baseada no conhecimento e um importante indutor do desenvolvimento social. Consequentemente, uma universidade empreendedora não é apenas uma promotora de múltiplas medidas de apoio ao empreendedorismo, mas também é um desenvolvedor de técnicas, estratégias e posturas competitivas (GUERRERO; URBANO, 2012). É uma peça fundamental para desenvolver o espaço do conhecimento e, cada vez mais, os espaços de inovação e de empreendedorismo.

A cooperação entre universidade empresa se configura de diferentes formas, como: atuação de empresário junto a conselho de administração universitário; visitas de representantes das universidades às empresas; conselho consultivo participativo composto por diferentes segmentos da sociedade; pesquisas tecnológicas em parceria; destaque de empresários que são relevantes parceiros na interação com a instituição; prestação de serviços; serviços de consultoria e levantamento de dados por meio de pesquisas de campo; mesas redondas para discussões curriculares e de abordagens inovadoras; estágios de professores nas empresas, compartilhamento de equipamentos entre empresa e universidade; atividades que envolvam egressos que atuam nas empresas; sistematização de suporte à contratação de estagiários; polos, parques, incubadoras e trades; cursos de aperfeiçoamento; programas de gestão tecnológica; programas de educação continuada e educação à distância; utilização do estágio curricular supervisionado como disciplina para intercâmbio de conhecimento e consolidação de parcerias (LEMOS; CARIO, 2017).

Neste sentido, pode-se afirmar que a cooperação existente entre universidades e empresas se caracteriza como arranjo interinstitucional essencial na 
promoção de pesquisa e desenvolvimento científico que possibilita vantagens competitivas com menores custos e riscos (GUERRERO; URBANO, 2012). Estas alianças tornam-se cada vez mais importantes em virtude de fatores como: velocidade das inovações tecnológicas, a necessidade de novas possibilidades e inovações diante da escassez de recursos e o aumento da competitividade global (LEMOS; CARIO, 2017).

\section{Procedimentos Metodológicos}

Nesta seção estão explicitados: (i) o enquadramento metodológico desta pesquisa; (ii) os procedimentos técnicos para condução do estudo de caso; e, (iii) os procedimentos técnicos do projeto SolutionUp.

\section{ENQUADRAMENTO DA PESQUISA}

A presente pesquisa caracteriza-se como descritiva quanto a seus objetivos, tem abordagem qualitativa e como estratégia de pesquisa utilizou-se o estudo de caso.

De acordo com os objetivos, a pesquisa descritiva é realizada a partir de uma primeira aproximação com o tema. A partir do levantamento das características conhecidas que compõem o fenômeno, o objetivo da pesquisa descritiva é retratar um perfil preciso de pessoas, eventos ou situações (SAUNDERS et al., 2009).

No que se refere à abordagem utilizada, este estudo pode ser classificado como qualitativo uma vez que busca examinar as percepções para o aperfeiçoamento da compreensão das atividades sociais e humanas, valendo-se de caráter subjetivo (SAUNDERS et al., 2009).

Por fim, como estratégia de pesquisa, o estudo de caso será utilizado para aprofundar o conhecimento em relação ao objeto de pesquisa com o objetivo de ampliar e detalhar o conhecimento necessário para atingir os objetivos propostos (YIN, 2015). Desse modo, os procedimentos realizados para a condução do estudo de caso são detalhados na próxima seção, tais procedimentos são baseados na metodologia proposta por (CAUCHICK MIGUEL, 2007). 


\section{PROCEDIMENTOS TÉCNICOS PARA CONDUÇÃO DO ESTUDO DE CASO}

Cauchick Miguel (2007) apresenta uma proposta para a condução de um estudo de caso, sendo contempladas as seguintes etapas: (i) Definição de uma estrutura teórica-conceitual; (ii) planejamento dos casos; (iii) coleta de dados; (iv) análise dos dados; e, (v) elaboração do relatório.

Dessa forma, a primeira etapa para realização de um estudo de caso consiste na definição de um referencial conceitual-teórico para o trabalho, resultando, dessa forma, em um mapeamento da literatura sobre o assunto estudado (CAUCHICK MIGUEL, 2007).

Para a presente pesquisa, o mapeamento da literatura a respeito do assunto se deu por meio de pesquisas nas bases teóricas Scopus e Google Scholar com as palavras chaves "aprendizagem ativa", "active learning", "gestão de empresas de base tecnológica" e "Small- to medium-sized enterprises".

A partir da estruturação do portfólio bibliográfico e revisão da literatura foi possível identificar os constructos teóricos, elementos extraídos da literatura que representam um conceito a ser verificado empiricamente (CAUCHICK MIGUEL, 2007). Nesta pesquisa, com base na revisão de literatura a respeito de modelos de negócio, foi possível evidenciar 05 constructos que serão verificados empiricamente. A partir desse estudo, ao final do trabalho, é importante que seja realizado o cotejamento entre os constructos teóricos e os dados coletados em campo.

Finalizando a etapa de planejamento, passa-se a escolha das unidades de análise, ou seja, dos casos a serem estudados (YIN, 2015). O caso selecionado para este estudo é uma startup incubadas no MIDI Tecnológico.

Com a seleção do caso finalizada, deve-se determinar os métodos e técnicas tanto para a coleta quanto para a análise dos dados (CAUCHICK MIGUEL, 2007; YIN, 2015). Para esta pesquisa, foram realizadas entrevistas semiestruturadas e análise documental. A análise documental é constituída por documentos fornecidos pela empresa e pelas memórias de reunião.

Por fim, a partir do conjunto de dados coletados o pesquisador deve então elaborar o relatório final, no caso, o artigo final (CAUCHICK MIGUEL, 2007; YIN, 2015). Neste relatório, são elaboradas as comparações entre a teoria e observações práticas, ou seja, o cotejamento dos constructos teóricos evidenciados a partir da revisão de literatura e os dados coletados em campo. 


\section{PROCEDIMENTOS TÉCNICOS DO PROJETO SOLUTIONUP}

Em relação aos procedimentos adotados para a execução do projeto Solutionup foram baseados nas etapas definidas por Marquardt (2005), o qual oferta princípios e práticas que serviram como norte para aplicação empírica, tais práticas referidas na Figura 1.

Figura 1 Método de Aprendizagem em Ação.

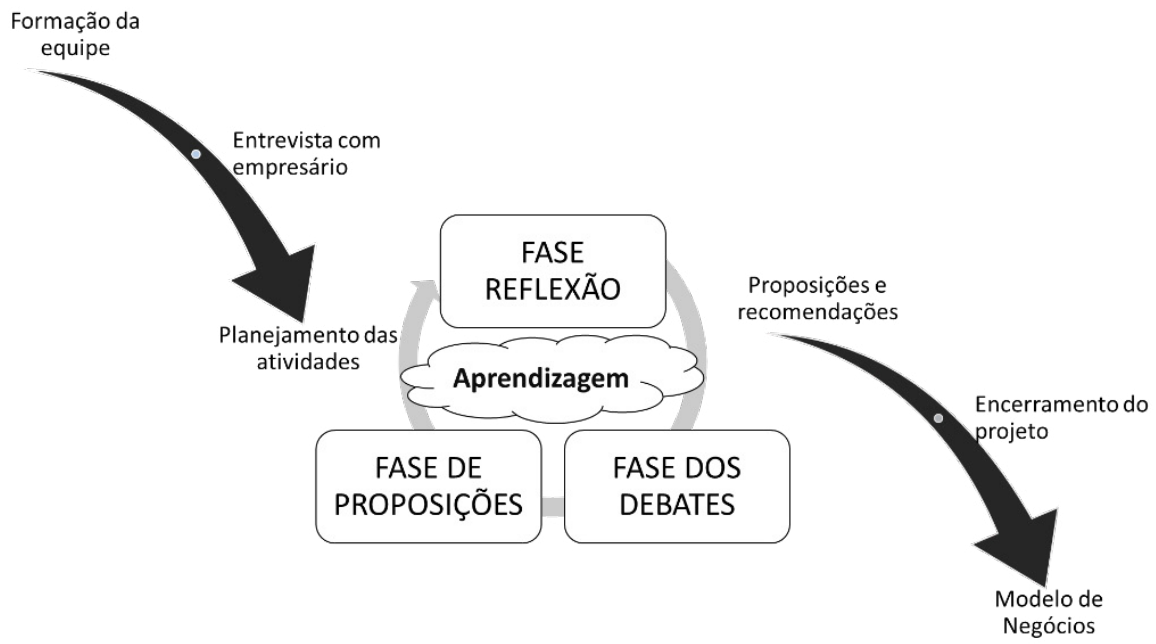

Fonte: Adaptado de Maquardt (2005).

$\mathrm{Na}$ primeira fase, denominada de formação da equipe de trabalho onde ocorre: (i) a prospecção de um ator externo (empresário) que possui interesse em compartilhar um problema organizacional; e, (ii) seleção de alunos que farão parte do ciclo do projeto.

A partir da formação da equipe, passa-se a fase do contato com o problema. Para isso, o ator externo realiza uma apresentação resumida sobre seu contexto e a dificuldade de gestão de sua empresa que este julga ser preciso resolver. Com esta apresentação, os alunos realizam perguntas abertas ao ator externo. Neste ponto, é preciso que o professor-facilitador instigue os alunos sobre quais disciplinas do currículo ou áreas de conhecimento que seriam úteis para ajudar a estruturar o referido problema. 
Deste modo, após a estabilização das áreas de conhecimento respetivas ao problema relatado pelo ator externo, passa-se ao planejamento das atividades. Este se dá quando os alunos são incentivados a se organizarem em grupos, aqui denominados de "comissões", de acordo com sua afinidade e interesse para cada área de conhecimento selecionada.

As comissões discutem os próximos passos, dentre eles:

I. Realizar visita técnica à organização;

II. Selecionar referencial bibliográfico sobre o tema;

III. Realizar benchmarking;

IV. Solicitar apoio de mestrando, doutorando ou egressos;

V. Solicitar depoimentos de quem já passou por situação similar;

VI. Solicitar palestras de experts sobre o tema;

VII. Realizar planos financeiros ou operacionais;

VIII. Elaboração de modelos de documentos ou processos;

IX. Elaboração de recomendações imediatas;

X. Solicitação de novas informações ao ator externo;

XI. Elaboração de apresentações para explicar ao ator externo como ele deveria proceder.

A seguir, inicia-se a primeira fase de reflexão, onde o professor-facilitador promove reflexões nos alunos sobre o que eles aprenderam a cada encontro, onde se documenta em um mapa mental (mapa cognitivo), como reflexões teóricas e práticas, riscos, pendências por falta de tempo, perguntas sem respostas, e polarizações de opiniões entre alunos.

$\mathrm{Na}$ fase seguinte, denominada de fase de debates e argumentações, o professor-facilitador orienta os alunos na busca do conhecimento necessário para elaborar as recomendações, onde encontros semanais são realizados para que os alunos exponham aos demais suas dúvidas e questionamentos. Os alunos são incentivados a procurarem materiais relacionados, como notícias, vídeos, casos similares, artigos de revistas empresariais, exposição de experiências pessoais e profissionais. 
Cada grupo de trabalho elabora apresentações para defender sua argumentação, enquanto os demais alunos realizam questionamentos, objeções e proposições de melhorias. O grupo de alunos decide quais elementos devem se transformar em proposições e quais devem ser retirados.

Na fase de proposições, o ator externo é convidado a assistir às apresentações dos alunos e de forma interativa realiza questionamentos e objeções às recomendações elaboradas pelos alunos. Por meio de um debate construtivo, mediado pelo professor-facilitador, as objeções são aceitas ou transpostas por meio de argumentação teórica e/ou criativa.

O grupo define as prioridades que cada recomendação aceita pelo ator externo, desta forma é acordado com o ator externo o próximo encontro, considerando o cronograma do projeto, para que um conjunto significativo de ações de intervenção possam ser implementadas e que possa ser dado um feedback aos alunos sobre os resultados e obstáculos que as ações de intervenção se defrontam. Neste ponto, se necessário, o ciclo retorna a fase de debates e reflexões até a estabilização das recomendações.

O encerramento do caso se dá quando: (i) a carga horária do projeto se encerra; (ii) quando os alunos entendem que não há mais oportunidades de aprendizado; (iii) quando o professor-facilitador entende que o problema não é relacionado com conhecimentos de áreas de conhecimento da Administração; ou, (iv) quando o ator externo entende que o problema foi endereçado a contento. Ao fim, lições aprendidas são elaboradas pelo grupo de alunos.

Por fim, esse projeto tem algumas premissas de trabalho que são utilizadas por essa pesquisa: (i) multidisciplinaridade; (ii) aprendizagem vivencial (construtivismo); (iii) colaboração; (iv) trabalhar com casos reais; (v) professor como facilitador; (vi) fomento à pesquisa; (vii) fomento à criatividade e inovação; (viii) integração da Universidade com Sociedade (CALVETTI; LACERDA; BERNARDES, 2019).

\section{Resultados}

A seguir será apresentada a evolução histórica do projeto SolutionUp e os principais aspectos relevantes do caso objeto de estudo deste artigo. 


\section{EVOLUÇÃO HISTÓRICA DO SOLUTIONUP}

Em 2015 surge na Universidade Federal de Santa Catarina, no departamento do curso de Administração, um projeto denominado "Aprendizagem em Ação" que tem como objetivo realizar a integração entre universidade e startups de base tecnológica de Santa Catarina, em que, inicialmente, os graduandos do curso de Administração se propõem a resolver um problema de gestão dessas empresas em até 12 semanas.

Neste contexto, devido à procura de muitos alunos e que já não se limitavam mais à apenas ao curso de Administração, em 2017 são realizadas algumas modificações no modus operandi do projeto e assim, passa-se a trabalhar com uma equipe multidisciplinar de alunos de diversos cursos da UFSC, alterando seu nome para SolutionUp.

Neste sentido, com a finalidade de exemplificar as alterações realizadas, o Quadro 2 apresenta a retrospectiva das principais informações das empresas que já foram atendidas pelo projeto e evidencia o crescente aumento na demanda dos alunos.

Deste modo, a seguir será descrito o caso da empresa atendida em 2017.1, apresentando os principais aspectos relevantes acerca do desenvolvimento do projeto.

\section{SOLUTIONUP 2017/1- EMPRESA C}

No primeiro semestre de 2017, uma equipe voluntária de 16 alunos atendeu uma empresa que oferece produtos e serviços aplicados ao controle de qualidade na indústria por meio de visão computacional.

A primeira etapa do projeto, denominado formação da equipe do trabalho, se dá com o primeiro contato entre os membros da equipe é para organização interna das atividades, como por exemplo, definir como e quais meios de comunicação serão usados. Sendo assim, os alunos optaram por utilizar as ferramentas Slack e Trello. O Slack foi utilizado como um ambiente de troca mútua de conhecimento, pois os alunos iam postando materiais e documentos que eram atrativos para o projeto e isso se tornou positivo pois era uma forma colaborativa de troca de conhecimento. A Figura 2 explicita este fato. 


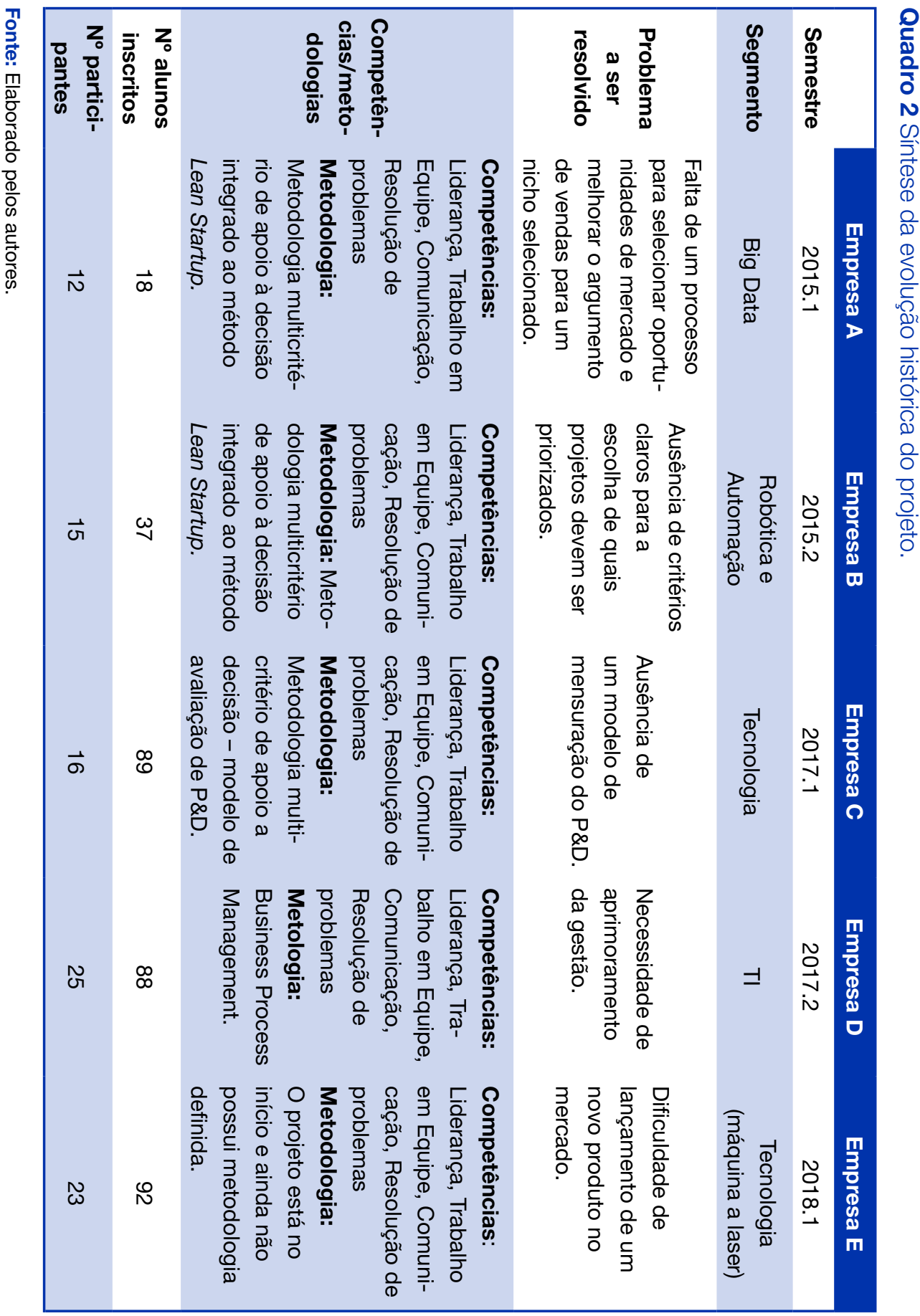


Figura 2 Slack como um ambiente colaborativo de troca de conhecimento.

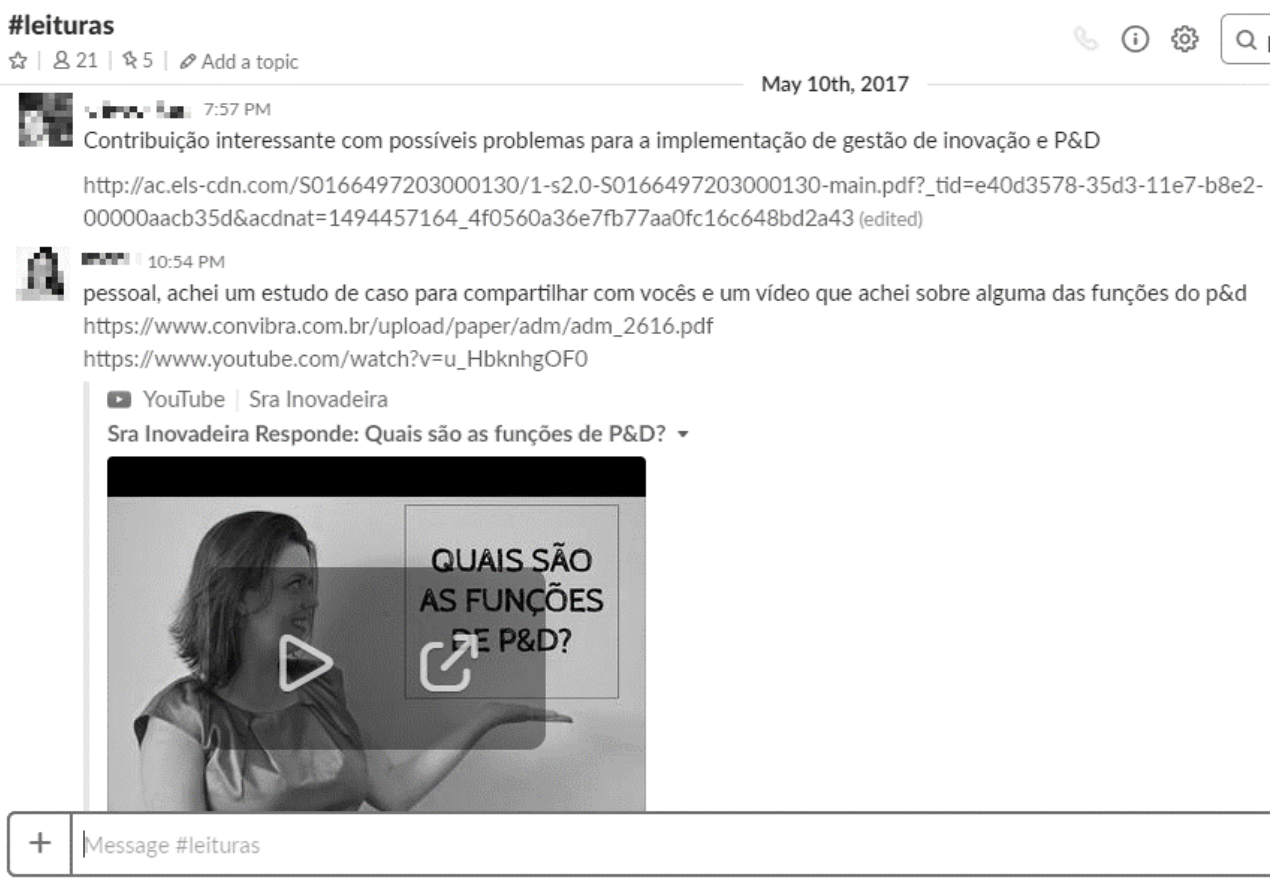

Fonte: Dados da pesquisa (2017).

Já o Trello foi utilizado para gerenciar as atividades que eram designadas a alguém, e desta forma, proporcionar maior eficiência na designação de tarefas e acompanhamento dos membros da equipe, visto que por meio desta ferramenta é possível acompanhar a evolução das atividades.

A partir disso, inicia-se a fase de contato com o problema, onde os gestores da empresa reúnem-se com a equipe do projeto. Os gestores dissertam a respeito do que possa ser o problema que a empresa vem enfrentando e para que esta reunião ocorra da maneira mais eficiente, a equipe de alunos elabora previamente um roteiro de perguntas que irão nortear a entrevista. Isto serve para que os alunos não divaguem durante a reunião e, assim, seja possível coletar as informações relevantes para que se comece a estruturar o problema enfrentado pela empresa.

Entretanto, a empresa atendida possuía uma particularidade, um dos gestores da empresa possui a formação acadêmica em Administração, e as reuniões 
acabavam se tornando uma aula dada pelo gestor, pois os alunos tinham dificuldade de se posicionar. Ao perder o controle da reunião, os alunos transmitiam insegurança, dando a falsa impressão de que não sabem o que estão fazendo, além de serem influenciados pelos pensamentos e intenções do gestor da empresa.

Em muitas situações, o gestor já estava direcionando as proposições de soluções, o que prejudicava a equipe. Essa dificuldade permeou alguns encontros com o gestor, ou seja, a equipe tinha grande dificuldade de identificar os momentos em que alguém precisava intervir para que a reunião não perdesse seu foco.

Desta forma, a partir das informações levantadas nas entrevistas inicia-se a fase de planejamento das atividades, os alunos rotularam o problema a ser resolvido como: "operacionalizar a estratégia e estruturar a gestão interna”. Assim os alunos se dividiram em comissões - pequenos grupos de alunos para realização de tarefas pontuais - para estudar como seria a resolução desse problema. Neste primeiro momento, foram designadas as comissões de: recursos humanos, estratégia, marketing e, gestão de processos e operações. O Quadro 3 abaixo sintetiza os assuntos estudados pelas comissões.

Quadro 3 Áreas de conhecimento estudados pelas comissões.

\begin{tabular}{|cll|}
\hline \multicolumn{1}{|c|}{ Comissão } & \multicolumn{1}{c|}{ Assunto abordado } \\
\hline \multirow{2}{*}{ Comissão de gestão de } & - 5 W2H \\
processos e operação & - Matriz Gut BÁsıCO \\
& - Diagrama de Ishikawa \\
& - Gestão de pessoas - ambiente de inovação - SCRUM \\
Comissão de Recursos & (gerenciar os produtos) \\
Humanos & - Gestão do conhecimento - conhecimento democrático \\
& - Ferramentas: drive + trello e Scrum \\
Comissão de Estratégia & OKR \\
& - Precificação - Baseada no valor \\
& - Suporte ao cliente - Técnica Delphi \\
Comissão de Marketing & Criar um CRM - Suporte ao cliente \\
& Estruturar um funil de vendas com utilização de venda \\
& pessoal - produto complexo \\
\hline
\end{tabular}

Fonte: Memórias de reunião do projeto. 
Essas comissões possuíam o prazo de uma semana para elaborarem suas pesquisas e assim, realizavam uma apresentação dos resultados na reunião seguinte. E, assim, para garantir a eficiência das comissões, foi repassada a recomendação de não encerrar a reunião sem organizar a comissão, com definição de líder, dias, horários e locais de encontro, para garantir que não haveria desencontros posteriormente. No entanto, apesar das recomendações, os alunos eram desorganizados e realizavam as atividades muito próximo da reunião seguinte, ocorrendo muitas vezes de a pauta da reunião e a decisão do que será apresentado ser tomada nas horas antecedentes à reunião, e este fato se repetia constantemente ao longo do projeto.

Seguindo, cada comissão realizou então uma apresentação com as informações coletadas de cada área de conhecimento e técnicas que podem ser aplicadas a fim de propor ações a empresa. Assim, os debates se iniciam com o propósito de identificar que área de conhecimento iria atender o problema apresentado.

No entanto, na fase de debates e argumentações com a presença dos gestores, estes explicaram que embora haja falhas em sua gestão, o que mantem a empresa é o setor de Pesquisa e Desenvolvimento - P\&D. Em uma das reuniões o gestor esclareceu:

“...a gestão é o nosso $20 \%$, o P\&D é o nosso $80 \%$, então a gente precisa de ajuda no nosso 80 , pois o 20 conseguimos arrumar depois".

A partir disso, a equipe teve de estruturar um novo problema, realizar novas pesquisas e pode verificar que a empresa não possuía métricas de acompanhamento do setor de P\&D. Deste modo, a nova rotulação do problema que foi validada pelos gestores: “Estruturar modelo de mensuração de $P \& D$ ”. Aqui começou uma nova jornada para os alunos, pois o foco das comissões teria que mudar.

A nova fase de debates e argumentações iniciou com o desenvolvimento do conhecimento dos participantes sobre avaliação de desempenho. Os alunos realizaram uma pesquisa sobre indicadores e critérios de sucesso na gestão do P\&D e selecionaram os que mais se adequavam a realidade da empresa, a partir deste momento inicia-se então a fase de proposições. 
Após a seleção dos indicadores e critérios, ocorreu a validação destes com os gestores. Os gestores defiram ainda escalas e presos de cada critério para a construção do modelo de avaliação. Por fim, os alunos apresentam aos gestores o modelo de avaliação de desempenho para gestão do P\&D proposto.

Juntamente ao modelo, foi entregue ainda um relatório apresentando o sistema de gestão desenvolvido para o P\&D da empresa, explicitando a natureza dos indicadores, suas respectivas escalas e pesos. Ademais, consta ainda no relatório um manual de utilização de uma planilha em excel para os cálculos necessários para atualização da ferramenta proposta.

\section{Discussão do Caso}

Ao passo em que o projeto se desenrolava, os pesquisadores puderam observar que a equipe de alunos apresentava alguns comportamentos, que podem ser observados na figura 3.

Figura 3 Mapa mental: Comportamentos observados entre os membros

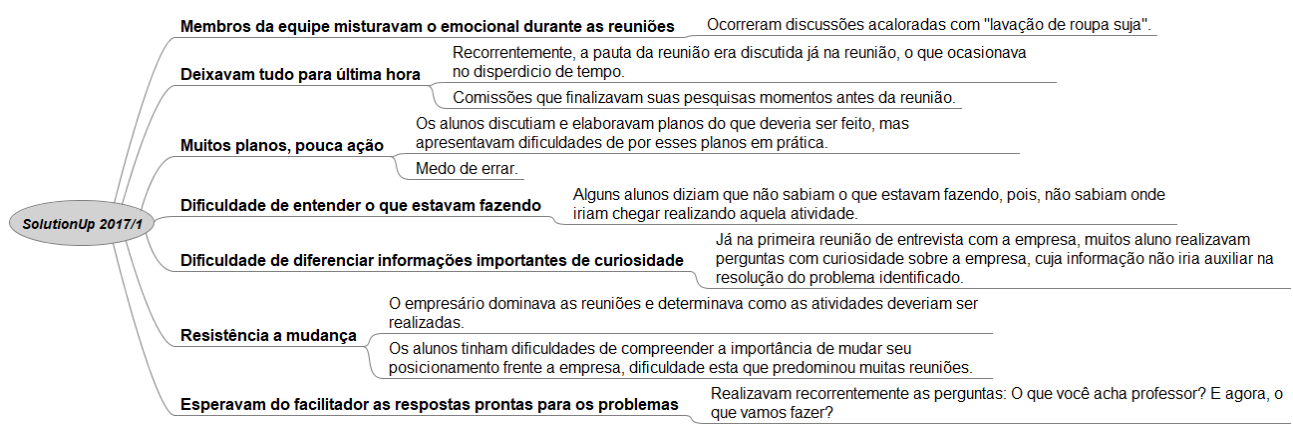

Fonte: Elaborado pelos autores.

Como apresentado na figura 3 , um dos comportamentos observados pelos pesquisadores nos alunos foi a dificuldade de colocar em prática o planejado. A equipe planejava as atividades e tinha dificuldade de colocá-las em prática devido a intenção de fazer sem erros na primeira tentativa. Entretanto, um aspecto impor- 
tante nessa característica de planejar e não colocar em prática é que a partir do erro que se encontra a solução de um problema e, que não querer demonstrar fraqueza ou assumir um erro cria barreiras que podem impedir o sucesso.

Semelhante a esta situação, outro comportamento perceptível é o de prosseguir nas reuniões mesmo sem entender o que estava ocorrendo, pois mesmo com o projeto já avançado, ainda haviam alunos que não sabiam o objetivo das atividades. Isso impactava no andamento do projeto, mas principalmente na aprendizagem do aluno, pois eles desenvolviam as atividades de forma mecanicista isentos de criticidade por não entender o que se passava.

Neste sentido, é importante que os alunos sejam estimulados a desenvolver o senso crítico e que o conhecimento é fruto de uma ação, ou seja, somente indo a campo e realizando algumas pesquisas é que as dúvidas poderiam ser respondidas. Não cabe nem a uma pessoa mais experiente ou até mesmo empresários de sucesso o fornecimento de respostas, mas sim, a busca dos caminhos e dos métodos para que o aluno, por si mesmo, obter as suas respostas que provocaram a sua motivação em continuar aprendendo.

Outro comportamento observado foi a desorganização dos alunos em relação as atividades internas do projeto. A procrastinação era observada frequentemente, muitas atividades eram realizadas as vésperas da data de entrega estipulada e em muitas situações a decisão sobre pauta de reunião minutos era tomada minutos antes desta. Estes fatos faziam com que a reunião fosse ineficiente e tivesse tempo reduzido afim de organizar o que deveria ter sido feito antes.

Neste sentido, em muitos momentos os alunos tinham dificuldade de mediar os encontros com a empresa. Ao perder o controle da reunião, os alunos transmitiam insegurança, dando a falsa impressão de que não sabem o que estão fazendo, além de serem influenciados pelos pensamentos e intenções do gestor da empresa. Dessa forma, entre os alunos precisava emergir um líder que possa realizar essa mediação fazendo as devidas intervenções.

Outro comportamento importante observado foi que, em situações calorosas, em que os ânimos estavam exaltados, devido a divergências de opinião, os alunos não conseguiam deixar o lado pessoal e destacar o profissional, ocasionando discussões pessoais em meio reunião. Ânimos exaltados e pessoas chateadas com algo que foi dito sem a intenção, são grandes empecilhos nas tomadas de decisão. 
Por fim, a partir do caso apresentado, e dos principais comportamentos identificados durante a aplicação do método proposto pelo projeto, é possível realizar a análise dos dados com base nos constructos teóricos identificados previamente e identificar as principais lições aprendidas, conforme apresentado no Quadro 4.

Quadro 4 Lições aprendidas do projeto.

\section{Constructo}

Evidência prática

Constructo 01: Como for- Em prática, foi observado ma de uma aprendizagem que muitos alunos puderam efetiva, é preciso que os desenvolver sua capacidade alunos desenvolvam sua crítica ao longo do desenvolcapacidade crítica, de sín- vimento do projeto. O facilitese, de conceituação e de tador era visto como a fonte autonomia realizando tarefas de respostas as dificuldades mentais de alto nível, como que eram encontradas e asanálise, síntese e avaliação.

\section{Constructo 02: $O$ aluno} deve assumir a responsabilidade sobre decisões que influenciam seu aprendizado, deste modo, deve ter escolha sobre as atividades de aprendizagem que quer desempenhar, monitorando e avaliando o seu próprio progresso. sim, muitos alunos tinham dificuldade de entender 0 que estava sendo feito e como a dificuldade poderia ser superada.

A dinâmica do projeto incentivava os alunos a participarem de comissões de acordo com sua afinidade e curiosidade acerca do tema de pesquisa.

As comissões realizavam uma apresentação com as informações coletadas de cada área de conhecimento e técnicas que poderiam ser aplicadas a fim de propor ações a empresa. E assim, os debates eram embasados em conhecimentos e informações obtidas por estes alunos.

\section{Lições aprendidas}

"Devemos errar, e não só uma vez, o erro deve ser constante."

É a partir do erro que se encontra a solução para o problema. Problemas existem para todos, ninguém é perfeito, mas ninguém quer demonstrar fraqueza nem assumir que pode errar, e isso acaba criando barreiras que podem impedir o sucesso.

"Somos uma equipe e a ajuda de todos os membros é de suma importância"

É preciso empenho da equipe acima de tudo. Além disso, o incentivo a participação dos membros faz com que estes possam ser condutores de seu conhecimento, pesquisando sobre temas de seus interesses estes possam adquirir conhecimento teórico e prático que muitas vezes não é possível ser adquirido em sala de aula. 
Constructo 03: A partir dos avanços tecnológicos, pode-se propiciar aos alunos ferramentas para a execução de atividades como técnica de incentivo a aprendizagem, como por exemplo, canais de discussão, fóruns de conteúdos e compartilhamentos de arquivos.
Para o projeto, a utilização de ferramentas que auxiliam na comunicação da equipe e compartilhamento de documentos foi de suma importância. Neste sentido, ao utilizar essas ferramentas, o contato entre os membros do projeto se dá não só durante as reuniões semanais, mas sim diariamente. Essa agilidade na comunicação proporciona a equipe uma capacidade de resolução de problemas mais ágil, ou seja, caso ocorra um problema ou algum membro enfrente alguma dificuldade ou tenha alguma dúvida, este pode ser resolvido de forma até mesmo imediata, não sendo necessário aguardar a próxima reunião.
"Definir no início do projeto os papéis de gerenciamento das ferramentas utilizadas."

Estes indivíduos, serão os encarregados por organização dos arquivos e cobrança dos membros. Ter essa organização e cobrança, por mais que às vezes chega a ser desgastante, ajuda as pessoas a lembrarem de seus compromissos e a se organizarem.

\section{"É necessário que todo material do projeto esteja disponível para todos os membros."}

Todos os membros do projeto devem ter acesso pleno a toda informação. Como complemento, todo documento editado, não deve se sobrepor a sua versão anterior, para isso cada nova versão deve ser salva com a data do dia de edição no nome do arquivo, para então ter as duas versões. Isso permite comparar os documentos sem perder informações e a documentação da evolução do projeto. 
Constructo 04: As práticas de gestão propostas para EBTs devem ser recomendadas a partir da consideração de suas especificidades.

\section{Constructo 05: O decisor possui papel fundamen- tal, pois ele é a pessoa que exerce responsabilidade e a autoridade necessária para a tomada de decisão na orga- nização.}

Conforme observado no caso, a participação ativa da empresa durante o projeto é fundamental. É a partir das informações apresentadas por ela que os alunos obtêm subsidio para a identificação do problema a ser resolvido e qual técnica pode ser adaptada ao contexto da empresa.

Entretanto, é necessário que a equipe consiga delimitar a partição da empresa durante $o$ desenvolvimento do projeto. A participação demasiada e o excesso de informações podem acarretar em atrasos e até mesmo desfocar as atenções do real problema.
"Se possível, todos os membros deveriam participar de pelo menos uma visita técnica a empresa. "

O acompanhamento in loco aproxima os membros da empresa com a equipe do projeto e tornar seus processos mais palpáveis para a equipe.

\section{"Não devem ser realizados encontros sem a presença da empresa"}

A entrevista com o cliente, bem como sua participação na reunião enriquecem a discussão de detalhes, exemplos e torna processos (tomada de decisão, validação de decisões e etc.) mais ágeis. Uma vez que o cliente sabe o que está acontecendo e acompanha a elaboração do produto final, ele sabe o que esperar.
A participação do decisor é essencial durante o decorrer do processo. Conforme visto no caso, foi a partir das apresentações semanais do desenvolvimento dos processos que o decisor pode identificar que o real problema a ser resolvido era outro, e assim, pode-se realizar os ajustes no foco e resultados pretendidos do projeto.

Fonte: Elaborado pelos autores. 


\section{Considerações Finais}

A partir do contexto em que estas EBTs estão inseridas, surge a necessidade de projetos de pesquisa e extensão que auxiliem estas empresas a utilizarem novos conceitos, tendências e ferramentas para seu sucesso empresarial, no contexto de um programa universitário que se centra em uma abordagem de aprendizagem ativa (CALVETTI; LACERDA; BERNARDES, 2019).

Deste modo, esta pesquisa se destinava a evidenciar os fatores críticos de sucesso na aplicação de um método de aprendizagem pela ação em um projeto de extensão na Universidade Federal de Santa Catarina, tendo como seguintes objetivos específicos: i) propor um método de aprendizagem ativa para aperfeiçoar competências em alunos de graduação; ii) explanar os resultados da execução de um projeto de extensão se valendo do método proposto; iii) triangular evidências para propor aspectos críticos do método de uma forma indutiva.

O primeiro objetivo específico pode ser observado na seção de procedimentos metodológicos, onde foram evidenciados os procedimentos técnicos do projeto SolutionUp. O método proposto é baseado em premissas da aprendizagem ativa, tema este apresentado na seção de fundamentos teóricos.

Seguidamente, foram apresentados os resultados da aplicação do método, apresentado na seção de resultados. Para isso, primeiramente, apresentou-se uma retrospectiva temporal do projeto desenvolvido, exemplificando as competências e metodologias já trabalhadas, assim como dados quantitativos e qualitativos dos alunos inscritos e participantes.

Desse modo, no primeiro semestre de 2017, uma equipe voluntária de 16 alunos uma empresa que oferece produtos e serviços aplicados ao controle de qualidade na indústria por meio de visão computacional. Por se tratar de uma empresa de tecnologia, seu core business é a inovação tecnológica.

Já o terceiro objetivo específico pôde ser observado na seção de discussão dos resultados, onde buscou-se identificar quais os aspectos críticos de sucesso para a aplicação do método de aprendizagem ativa. Uma das dificuldades apresentadas pelos alunos era o medo do fracasso apresentado pelos alunos, provocado pela busca de uma solução ótima e genérica do problema a partir da 
literatura científica ou de exemplos semelhantes, típicos dos métodos tradicionais de aprendizagem.

Neste sentido, é importante que os alunos sejam estimulados a desenvolver o senso crítico e que o conhecimento é fruto de uma ação, ou seja, somente indo a campo e realizando algumas pesquisas é que as dúvidas poderiam ser respondidas. Não cabe nem a uma pessoa mais experiente ou até mesmo empresários de sucesso o fornecimento de respostas, mas sim, a busca dos caminhos e dos métodos para que o aluno, por si mesmo, obter as suas respostas que provocaram a sua motivação em continuar aprendendo.

A singularidade do problema, aliada à limitação de dados e conhecimentos, levou o grupo a decidir mais sobre estudos em in loco do que pesquisas bibliográficas genéricas sobre o problema ou a busca de soluções semelhantes. Deste modo, os desafios a serem superados emergem de forma indutiva, ou seja, os alunos estão em contato direto com o problema e precisam ser proativos quanto a proposição de recomendações e de que ações devem ser realizadas, estimulando dessa forma, o senso crítico, a capacidade de resolução de problemas e o aprendizado continuo.

Deste modo, ao identificar estes comportamentos, e a partir das evidências práticas a partir da realização do estudo de caso, é possível observar que a dinâmica proposta pelo projeto estimula o desenvolvimento de uma visão prática de resolução de problemas nos alunos. O projeto permitiu que os alunos compreendessem a dinâmica de uma startup, os desafios e decisões na construção de um modelo de negócio além de estimular o aprendizado. A aprendizagem pela ação visa que o aluno seja o principal agente da construção de seu conhecimento e não apenas um receptor de dados e informações, neste sentido, é preciso que o incentivo a este aluno seja feito de forma recorrente, e assim subsidiar as ferramentas necessárias para que este possa desenvolver não só seu conhecimento teórico, mas também suas competências práticas.

Por fim, como oportunidades de pesquisas futuras, recomenda-se a exemplificação de outros casos de aplicação do método proposto, visando identificar outros comportamentos relevantes, assim como uma síntese detalhada dos principais desafios enfrentados pelos alunos durante o processo. É possível ainda uma análise transversal e longitudinal dos casos e a comparação e variações apresentadas do método aplicado a cada caso. 


\section{Agradecimentos}

O presente trabalho foi realizado com apoio do CNPq, Conselho Nacional de Desenvolvimento Científico e Tecnológico - Brasil e com apoio da Coordenação de Aperfeiçoamento de Pessoal de Nível Superior - Brasil (CAPES) - Código de Financiamento 001.

\section{Referências Bibliográficas}

ARTINGER, F. et al. Heuristics as adaptive decision strategies in management. Journal of Organizational Behavior, v. 36, n. S1, p. S33-S52, 2015. DOI: 10.1002/job.1950

BARON, L. Authentic leadership and mindfulness development through action learning. Journal of Managerial Psychology, v. 31, n. 1, p. 296-311, 2016. DOI 10.1108/JMP-04-2014-0135

BELL, B. S.; KOZLOWSKI, S. W. Active learning: effects of core training design elements on self-regulatory processes, learning, and adaptability. Journal of Applied psychology, v. 93, n. 2, p. $296,2008$. DOI:10.1037/0021-9010.93.2.296

BENI, P. F. et al. Processo de ensino-aprendizagem e a interação de professores e alunos em um curso de graduação em Administração de Empresas. Administração: Ensino e Pesquisa, v. 18, n. 2, p. 345-374, 2017. DOI: https://doi.org/10.13058/raep.2017.v18n2.565

CALVETTI, E. S.; LACERDA, R. T. O.; BERNARDES, M. L. Um estudo bibliométrico sobre avaliação de desempenho no processo de desenvolvimento ágil de software sob a perspectiva do construtivismo. Revista Brasileira de Gestão e Inovação, v. 6, n. 3, p. 1-28, 2019. DOI: 10.18226/23190639.v6n3.01

CANOPF, L. et al. Prática docente no ensino de administração: analisando a mediação da emoção. Organizações \& Sociedade, v. 25, n. 86, p. 371-391, 2018. DOI: 10.1590/1984-9250862

CAUCHICK MIGUEL, P. A. et al. Estudo de caso na engenharia de produção: estruturação e recomendações para sua condução. Revista Produção, v. 17, n. 1, p. 216-229, 2007. DOI: http://dx.doi.org/10.1590/ S0103-65132007000100015

CHANDLER, G. N.; BROBERG, J. C.; ALLISON, T. H. Customer value propositions in declining industries: Differences between industry representative and high-growth firms. Strategic Entrepreneurship Journal, v. 8, n. 3, p. 234-253, 2014. DOI: https://doi.org/10.1002/sej.1181

DE LIMA, T. B. et al. Dimensões de um sistema de aprendizagem em ação para o ensino de administração. Administração: ensino e pesquisa, v. 13, n. 1, p. 11-46, 2012. DOI: https://doi.org/10.13058/ raep.2012.v13n1.97

GOMES, L. A. de V. et al. How entrepreneurs manage collective uncertainties in innovation ecosystems. Technological Forecasting and Social Change, v. 128, p. 164-185, 2018. DOI: https://doi.org/10.1016/j. techfore.2017.11.016 
DIAS, L. C.; TSOUKIÀS, Alexis. On the constructive and other approaches in decision aiding. In: Proceedings of the 57th meeting of the EURO MCDA working group. 2003.

ENSSLIN, L.. et al. Avaliação do desempenho de empresas terceirizadas com o uso da metodologia multicritério de apoio à decisão-construtivista. Pesquisa Operacional, v. 30, n. 1, p. 125-152, 2010. DOI: http://dx.doi.org/10.1590/S0101-74382010000100007

ETZKOWITZ, H.; ZHOU, C. Hélice Tríplice: inovação e empreendedorismo universidade-indústria-governo. Estudos avançados, v. 31, n. 90, p. 23-48, 2017. DOI: 10.1590/s0103-40142017.3190003

GUERRERO, M.; URBANO, D. The development of an entrepreneurial university. The journal of technology transfer, v. 37, n. 1, p. 43-74, 2012. DOI: 10.1007/s10961-010-9171-x

HUDSON, M.; SMART, A.; BOURNE, M. Theory and practice in SME performance measurement systems. International journal of operations \& production management, v. 21, n. 8, p. 1096-1115, 2001. DOI: https://doi.org/10.1108/EUM0000000005587

KRAKAUER, P. V.; DOS SANTOS, S. A.; DE ALMEIDA, M. I. R. Teoria da aprendizagem experiencial no ensino de empreendedorismo: um estudo exploratório. Revista de Empreendedorismo e Gestão de Pequenas Empresas, v. 6, n. 1, p. 101-127, 2017. DOI: http://dx.doi.org/10.14211/regepe.v6i1.353

LACERDA, R. T. de O. et al. Research opportunities in business process management and performance measurement from a constructivist view. Knowledge and Process Management, v. 23, n. 1, p. 18-30, 2016. DOI: 10.1002/KPM.1495

LACERDA, R. T. de O. et al. Innovative integration between incubated startups and universities to achieve continuous competitive advantages in dynamic environments. Navus-revista de gestão e tecnologia, v. 7, n. 2, p. 78-96, 2017. DOI: 10.22279/NAVUS.2017.V7N2.P78-96.497

LACERDA, R. T. de O. et al. Perspectivas de pesquisa sobre avaliação de desempenho e gerenciamento de projetos. Revista de Gestão e Secretariado, v. 9, n. 2, p. 96-125, 2018. DOI: https://doi.org/10.7769/ gesec.v9i2.680

LANDRY, M. A note on the concept of problem. Organization Studies, v. 16, n. 2, p. 315-343, 1995.

LEONARD, H. S. Understanding the causal path between action, learning, and solutions: maximizing the power of action learning to achieve great results. Action Learning: Research and Practice, v. 12, n. 1, p. 22-36, 2015. DOI: https://doi.org/10.1080/14767333.2014.977222

LEONARD, H. S.; LANG, F. Leadership development via action learning. Advances in Developing Human Resources, v. 12, n. 2, p. 225-240, 2010. DOI: $10.1177 / 1523422310367800$

LEMOS, D. C.; CARIO, S. A. F. Os sistemas nacional e regional de inovação e sua influência na interação universidade-empresa em Santa Catarina. REGE-Revista de Gestão, v. 24, n. 1, p. 45-57, 2017. DOI: 10.1016/j.rege.2016.05.002

MARAFON, A. D. et al. The effectiveness of multi-criteria decision aid methodology: A case study of R\&D management. European Journal of Innovation Management, v. 18, n. 1, p. 86-109, 2015. DOI: 10.1108/ EJIM-10-2013-0106

MARQUARDT, M. O poder da aprendizagem pela ação: como solucionar problemas e desenvolver líderes em tempo real. Tradução Anna Lobo. Rio de Janeiro: Ed. Senac Rio, 2005.

MOWERY, D. C. Universities in national innovation systems. Georgia Institute of Technology, 2005.

O'CONNOR, G. C.; RICE, M. P. A comprehensive model of uncertainty associated with radical innovation. Journal of Product Innovation Management, v. 30, p. 2-18, 2013. DOI: https://doi.org/10.1111/jpim.12060 
PERRITON, L.; REYNOLDS, M.. Critical Management Education in challenging times. Management Learning, v. 49, n. 5, p. 521-536, 2018. DOI: https://doi.org/10.1177/1350507618795090

$\mathrm{PICH}$, M. T.; LOCH, C. H.; MEYER, A. D. On uncertainty, ambiguity, and complexity in project management. Management Science, v. 48, n. 8, p. 1008-1023, 2002. DOI: https://doi.org/10.1287/mnsc.48.8.1008.163 ROY, B. Decision science or decision-aid science?. European journal of operational research, v. 66, n. 2, p. 184-203, 1993.

SAUNDERS, M. NK. Research methods for business students, 5/e. Pearson Education India, 2011.TEECE, David J. Business models, business strategy, and innovation. Long-range planning, v. 43, n. 2-3, p. 172-194, 2010. DOI: https://doi.org/10.1016/j.lrp.2009.07.003

TEECE, D. J. Dynamic capabilities: Routines versus entrepreneurial action. Journal of management studies, v. 49, n. 8, p. 1395-1401, 2012. DOI: https://doi.org/10.1111/j.1467-6486.2012.01080.x

URIAS, G. M. P. C.; DE AZEREDO, L. A. S. Metodologias ativas nas aulas de administraçao financeira: alternativa ao método tradicional de ensino para o despertar da motivaçao intrínseca e o desenvolvimento da autonomia. Administração: Ensino e Pesquisa, v. 18, n. 1, p. 39, 2017. DOI: https://doi.org/10.13058/ raep.2017.v18n1.473

YIN, R. K. Estudo de Caso: Planejamento e métodos. Bookman editora, 2015.

ZOTT, C.; AMIT, R. Business model innovation: How to create value in a digital world. GfK Marketing Intelligence Review, v. 9, n. 1, p. 18-23, 2017. DOI: 10.1515/gfkmir-2017-0003 